doi: 10.5209/rev_RCHA.2010.v36.1

\title{
Estudio introductorio Relaciones históricas hispano-estadounidenses: visiones del siglo $X X$ en clave cultural
}

\author{
Sylvia L. HiLton \\ Universidad Complutense de Madrid \\ slhilton@ghis.ucm.es
}

\begin{abstract}
RESUMEN
Este estudio presenta un dossier que analiza diversas manifestaciones del papel de la cultura en las conexiones contemporáneas entre España y los Estados Unidos, como contribución a las nuevas corrientes historiográficas sobre las relaciones culturales internacionales. Son relativamente escasas las publicaciones españolas sobre este tema, por lo que el propósito de este ensayo introductorio es revisar el contexto historiográfico en el cual se producen estas investigaciones, antes de comentar cada uno de los artículos y autores del dossier. Ofrece un balance de lo publicado en España desde el año 1999 sobre relaciones culturales hispano-estadounidenses. Halla que la mayoría de los estudios tienen como principal enfoque la documentación y el análisis de las percepciones del 'otro', e identifica los temas concretos que han aparecido dentro de dos grandes apartados: España vista por los estadounidenses, y los Estados Unidos en percepciones españolas.
\end{abstract}

Palabras clave: España, Estados Unidos, historiografía, relaciones internacionales, cultura, siglo XXsiglo XXI.

\section{Introductory Study.}

\section{Historical Spanish-U.S. Relations: Impressions of the Twentieth Century in Cultural Perspective}

\begin{abstract}
This study presents a dossier which analyzes diverse manifestations of the role of culture in contemporary relations between Spain and the United States, as a contribution to current historiographical approaches to international cultural relations. Spanish publications on this subject are relatively scarce, so the introductory essay aims to review the historiographical context in which the research has been produced, before commenting on each article and author of the dossier. It offers an overview of what has been published in Spain since 1999 on Spanish-U.S. cultural relations. It finds that the main approach of the majority of the published studies has been the documentation and analysis of perceptions of the 'other', and it identifies the specific subjects that have appeared under two broad headings: Spain as seen by the USAmericans, and the United States in Spanish perceptions.
\end{abstract}

Keywords: Spain, United States, Historiography, International Relations, Culture, 20th Century - 21st Century.

SUMARIO: 1. Relaciones culturales hispano-estadounidenses: diez años de historiografía española. 2. Imágenes de España vista por americanos. 3. Los Estados Unidos en percepciones españolas. 4. Presentación del dossier "España y los Estados Unidos: interpretaciones culturales contemporáneas". 5. Conclusiones. 6. Referencias bibliográficas. 
Las múltiples formas que adopta la interacción cultural se han convertido en campo predilecto de los investigadores que buscan nuevos enfoques para abordar la historia de las relaciones internacionales. No se trata sólo de analizar la función de la cultura en la diplomacia o las políticas interestatales. La historiografía actual explora afanosamente las conexiones culturales potenciadas por procesos internacionales como las migraciones demográficas, el trasvase de conocimientos y tecnologías, el lenguaje y los mensajes del discurso público (representado sobre todo por la propaganda y los medios de comunicación masiva), o la difusión y valoración en mercados internacionales de espectáculos deportivos, objetos de arte, y obras literarias o cinematográficas, por citar sólo unos pocos aspectos. No obstante, la interacción cultural es un campo de investigación que todavía está poco cultivado en la historiografía española sobre las relaciones hispano-estadounidenses. El propósito de este dossier es, pues, contribuir al conocimiento de las relaciones culturales internacionales del siglo XX, incidiendo concretamente en algunas conexiones entre España y los Estados Unidos ${ }^{1}$.

\section{RELACIONES CULTURALES HISPANO-ESTADOUNIDENSES: DIEZ AÑOS DE HISTORIOGRAFÍA ESPAÑOLA}

En España, los investigadores y las casas editoriales se interesan cada vez más por la historia estadounidense en general. Desde los años de 1970, se aprecia un aumento progresivo del volumen de la producción historiográfica acerca de los Estados Unidos junto con una mayor variedad de enfoques teóricos y temáticos. Muchos de los títulos publicados son traducciones de autores estadounidenses, franceses y otros extranjeros, pero van aumentando significativamente los trabajos de investigación de autoría española ${ }^{2}$. Tales novedades historiográficas son sin duda un reflejo de los procesos de democratización y modernización de la sociedad española desde la instauración del actual régimen político ${ }^{3}$.

En el caso concreto de las relaciones hispano-estadounidenses, hay un abrumador predominio de temas políticos, diplomáticos y militares. Un gran número de trabajos valiosos han visto la luz en años recientes, y no es posible hacer aquí mención de todos ellos. Eso sí, cabe señalar los temas que han suscitado mayor interés, y son: la participación española en la guerra de independencia de los Estados Unidos; las tensiones provocadas por el temprano expansionismo territorial de la joven república hacia fronteras coloniales españolas; la intervención estadounidense en la crisis colonial española de 1895-1899; y ya en el siglo XX, además de algunos estudios generales, las investigaciones se han centrado en las relaciones diplomáticas hispano-estadounidenses durante la guerra civil española, la segunda guerra mundial, y la

${ }^{1}$ Se agradece la ayuda del programa Santander - UCM al grupo de investigación 930580 (Gr58/08) y la financiación por el MICINN del proyecto HAR2009-13284.

2 Para la bibliografía histórica y científico-social publicada entre 1980 y 1993, véase HiLTON, 1994, y para los años 1994-1996, véase PAREDES et al, 1996. Desde 2006, el Grupo de Investigación UCM dedicado a la Historia y Cultura de los Estados Unidos viene desarrollando un proyecto de recopilación sistemática retrospectiva de la historiografía publicada en España sobre los Estados Unidos.

3 Véase HiLton, 2007. 
guerra fría, con especial predilección por el asunto de las bases militares americanas en territorio español; y por último, las repercusiones sobre las relaciones hispanoestadounidenses de la pertenencia española a la Unión Europea. La historiografía más reciente publicada en España también aborda otros aspectos de las conexiones históricas hispano-estadounidenses. Los más destacados son la presencia española entre las raíces coloniales norteamericanas, la emigración española a los Estados Unidos (sobre todo el exilio de intelectuales republicanos), y las relaciones económicas y empresariales contemporáneas. Ahora bien, para poder apreciar bien el enfoque de este dossier lo que más nos interesa destacar son los aspectos culturales de las relaciones entre los dos países. Por eso se ofrece aquí un balance de la historiografía publicada en España sobre ese tema en los últimos diez años ${ }^{4}$.

Si bien el papel de la cultura es uno de los enfoques que mayor fascinación ejerce actualmente sobre los historiadores y analistas de las relaciones internacionales, es difícil delimitar su alcance. Se debaten cuestiones teóricas sobre el concepto de interacción cultural, sus variadísimas formas de manifestación y desarrollo en las conexiones entre diferentes naciones o sociedades, y su importancia como factor en las relaciones diplomáticas y bélicas entre estados 5 . Se estudian procesos tales como el imperialismo cultural y diversas políticas concebidas para difundir los propios valores y productos culturales en otros países; las formas de aceptación social de influencias culturales ajenas, o bien la resistencia social y/o la oposición gubernamental a su penetración; el papel en la diplomacia cultural de diversos medios que pueden servir para ejercer presión o para difundir propaganda ideológica, como son los medios de comunicación masiva, los estudios académicos en universidades propias y extranjeras, las redes culturales de todo tipo y, en definitiva, cualquier conexión que sea susceptible de convertirse en instrumento del "poder blando".

No es fácil encontrar un esquema sencillo para encajar todas las facetas del tema, de modo que en este estado de la cuestión, habrá lagunas temáticas y saltos en el tiempo, ausencias y silencios historiográficos, cuya potencialidad queda sólo sugerida por los trabajos mencionados aquí. Como punto de arranque puede servir un estudio sobre la pervivencia del derecho español en el sistema jurídico decimonónico de la Luisiana (LECUONA, 2006). Es un ejemplo bien interesante de las muy diversas huellas e influencias culturales que perduraron en grandes regiones de Norteamérica a resultas de la colonización española, que tuvieron repercusiones en los actuales Estados Unidos, y que son susceptibles de ser objeto de análisis historiográficos y científico-sociales.

No abundan los estudios generales sobre las relaciones culturales hispano-estadounidenses. Sobre el siglo XX, se ha publicado uno de enfoque más teórico (NIÑo, 2005), y otro centrado en el período de 1945-1953 (Delgado, 2003). Tampoco se han producido muchos análisis de tipo comparativo, pero cinco publicaciones recientes reflejan una sugerente diversidad temática. Del excepcionalismo de los Estados

\footnotetext{
${ }^{4}$ Esta propuesta alarga lo que de otro modo sería una breve introducción, pero creemos que la relativa escasez de publicaciones españolas sobre este tema justifica el esfuerzo por ofrecer una visión de conjunto, por lo menos representativa si no exhaustiva, para apreciar el contexto historiográfico en el cual se producen los artículos de este dossier.
} 
Unidos se ha escrito hasta la saciedad, pero seguir su evolución en relación con la no menos desarrollada idea del carácter excepcional del pueblo español ayuda a comprender muchos aspectos de las relaciones históricas hispano-estadounidenses (ISBELL, 2001). La comparación de artistas y tipos o temas concretos de obras artísticas sin duda ofrece un gran campo para estudiar las influencias culturales mutuas, en este caso las crucifixiones de Bacon y Barceló (SABALETE, 2002). La influencia del pensamiento científico sobre intelectuales españoles y estadounidenses a finales del siglo XIX ofrece significativos puntos de conexión que sugieren la utilidad de realizar análisis comparativos (MAESTRO, 2003). Igualmente tienen gran interés las comparaciones de sistemas educativos y programas de formación intelectual y profesional (SALVADOR, 2002). No sólo contribuyen al conocimiento de similitudes y diferencias culturales sino que sirven para sopesar objetivos, métodos y resultados de la enseñanza, con vistas a reformas sistémicas, y posiblemente contribuyan a comprender mejor ciertos procesos de homogeneización que forman parte del actual proceso de globalización. Las conexiones y los intercambios (tanto personales como profesionales) entre intelectuales españoles y estadounidenses ofrecen otro amplio campo temático para la investigación. Por ahora, parece que motiva más el tema del exilio de los intelectuales republicanos españoles en los Estados Unidos después de la guerra civil (NiÑo, 2007; RuEdA, 2009; FABER - MARTínez-CARAZO, 2009). No obstante, también han aparecido trabajos sobre intelectuales norteamericanos en España (ORTIZ GARCÍA, 2007), y sobre la cooperación política para fomentar los intercambios educativos en los años de 1960 (RoDRÍGUEZ JIMÉNEZ, 2007).

Sin embargo, es en el gran tema de las percepciones del 'otro' donde encontramos las principales aportaciones historiográficas y científico-sociales publicadas en España sobre relaciones culturales. El estudio de las percepciones del 'otro' ofrece la posibilidad de manejar una amplísima gama de conceptos y fuentes, pero aunque cambien los períodos cronológicos y los tipos de documentación, la idea central suele ser que la imágen del "otro" revela tanto o más sobre el que mira que sobre el mirado. Varios trabajos intentan abordar las perspectivas de ambas sociedades, en sus análisis de percepciones mutuas actuales (VALERO, 2002; ALONSO ZALDÍvAR, 2003; Chislett, 2005a). Ahora bien, es más fácil acometer este complicado tema desde una u otra perspectiva -española o estadounidense-, por lo que la mayoría de las publicaciones adopta este método.

\section{IMÁGENES DE ESPAÑA VISTA POR AMERICANOS}

Los estereotipos sobre los españoles y su cultura aparecieron muy pronto en el discurso público estadounidense (CASTILLO, 2002), sin duda por la continuidad en el siglo XIX de una línea de pensamiento de herencia británica. Parece que hubo una leve mejora de la imagen española en los Estados Unidos durante el primer tercio del siglo XX, pero los acontecimientos en España se aunaron a la persistencia de los antiguos prejuicios angloamericanos para mantener las imágenes negativas hasta el final del franquismo (SÁNCHEZ MANTERO, 1998a y 1998b). Intereses de todo tipo intervinieron en la forma de ver y hablar de España que se desarrolló en determinados sectores sociales norteamericanos, tanto en el siglo XIX como en el siglo XX 
(PAYNE, 2003 y 2010), pero después de la guerra de 1898, la guerra civil española fue el proceso histórico que más severamente puso a prueba la capacidad de comprensión de la sociedad estadounidense (JACKSON, 2001). Un amplio análisis de la imagen de España en la opinión pública estadounidense contemporánea demuestra cómo ha cambiado en años recientes, documentando la existencia de nuevos matices y mayor diversidad de percepciones (NOYA - RoDRíGUEZ - RUIZ 2008).

Un importante tipo de fuente para el tema de las percepciones es el relato de viaje. Los escritos de los viajeros o visitantes pretenden encapsular sus propias vivencias e impresiones personales, pero en realidad su visión y comprensión están condicionadas por el propio bagaje cultural. Por tanto, aunque en ocasiones la personalidad y el discernimiento del individuo hacen que su obra merezca un tratamiento especial, las coincidencias en un gran conjunto de tales relatos también pueden representar una tendencia de opinión más general. Durante la guerra de independencia de los Estados Unidos, John Jay viajó a España en calidad de representante 'oficial' del congreso revolucionario ante la Corte de Carlos III. Su misión diplomática ha sido estudiada por historiadores españoles, pero un reciente trabajo sobre los escritos de su esposa, Sarah Livingston Jay, refleja no sólo el temperamento y la ideología republicana de una mujer de la élite estadounidense, sino su forma de asumir las difíciles condiciones de su estancia en Madrid (De la Guardia, 2008). Entre los más tempranos visitantes estuvieron también John Adams y su hijo John Quincy Adams, ambos destinados a ser presidentes de su país (GonZÁLEz LóPEZ, 2005). Después llegaron Norman F. Tucker, Mordecai Noah, George Ticknor, Washington Irving, Caleb Cushing y Edward Everett, todos ellos con plumas harto expresivas de sus impresiones de España, contribuyendo a consolidar una serie de imágenes estereotípicas del país y sus gentes (SÁNCHEZ MANTERO, 2001). Otros muchos les siguieron. Buscaban (sobre todo en Andalucía) un exotismo colorista oriental, o las ruinas de una cultura antigua, misteriosa y romántica, o un primitivismo natural (GARCÍA-MONTÓN GARCÍA-ROMERAL, 2000). También viajaron y escribieron mujeres norteamericanas, añadiendo sus propias perspectivas a la imagen popular de España en su país (BigATEL, 2005).

Ahora bien, como ocurre en otros muchos países, también florece en la comunidad científica e intelectual de los Estados Unidos el hispanismo, dedicado a la investigación de la historia y la cultura de España, así como de todo el mundo hispánico. Los hispanistas tienden a partir de actitudes más medidas, cuando no claramente simpatizantes o incluso admiradoras de la cultura española, y sobre su trabajo han aparecido varios estudios recientes en publicaciones españolas (BOYD, 2000 y 2002; GiEst, 2004; FERNÁNDEZ, 2005).

El poderío de la lengua española en los Estados Unidos hoy es una cuestión palpitante que se refleja en los numerosos artículos y noticias que han ido apareciendo en los medios de comunicación españoles en años recientes. No es un aspecto solamente académico, sino una viva manifestación de la realidad social estadounidense que cuenta hoy con la presencia de numerosas comunidades hispanoamericanas. Es, pues, un tema que supera el ámbito de las relaciones culturales entre España y los Estados Unidos, y quizás por eso mismo reclama la atención del estado español, que ha patrocinado recientemente una enciclopedia del español en los Estados Unidos 
(López Morales, 2009). Es igualmente un tema atractivo para la comunidad científica española (CRIADO, 2004; OTERO, 2004), habiéndose producido al menos una importante investigación doctoral (VILAR GARCÍA, 2000 y 2003). Además, la historiografía vasca ofrece un enfoque diferente con un estudio lingüístico de los emigrantes vascos en el oeste norteamericano (LASAGABASTER, 2006).

El amplísimo tema de las influencias de la literatura española en la literatura estadounidense sobrepasa la obligada economía de este ensayo, pero a título meramente testimonial, citemos unos pocos estudios que vinculan lo literario con otros aspectos diversos de las relaciones culturales hispano-estadounidenses, como son: el interés por el teatro español en las universidades (LÓPEZ Mozo, 2006); las interpretaciones angloamericanas de El Quijote (VÁZQUEZ, 2006); y la promoción en la prensa periódica estadounidense de la novelística española durante el último cuarto del siglo XIX (CABALLER, 2007). Un caso particularmente llamativo de la relación de escritores españoles con la prensa estadounidense, así como con la naciente industria cinematográfica, fue el de Vicente Blasco Ibáñez, quien realizó una triunfal gira de conferencias en 1919-1920 y mantuvo negociaciones con William R. Hearst para escribir en sus periódicos, y con la Metro para la producción de películas basadas en sus obras (MIRA, 2004).

Otro campo temático que despega con fuerza como una faceta estelar de la historiografía de las relaciones culturales internacionales es todo lo relacionado con el mundo artístico. Se aprecia desde muy temprano la existencia de una alta valoración en los Estados Unidos del arte y de los artistas españoles, de sus temas y sus obras. La relación de Thomas Jefferson con España no se limitó a la compra de la Luisiana mientras fue presidente, sino que su curiosidad científica y técnica junto con su sentido estético como arquitecto ofrecen otra vertiente fascinante de una relación basada en su interés por las obras arquitectónicas españolas (FERNÁndEZ FERnÁndEZ, 2003). Hacia fines del siglo XIX, y con creciente fuerza una vez superada la crisis colonial española, aumentaron las conexiones culturales a través del arte. El coleccionismo artístico es una importante expresión del hispanismo estadounidense, si bien no se debe olvidar que tal actividad también expresa intereses que tienen poco que ver con el aprecio de sus valores estéticos, sobre todo en la primera mitad del siglo XX (MartíneZ Ruiz, 2009; KAGAN, 2007 y 2010; JiMÉNEZ-BLANCO, 2010). No fue Joaquín Sorolla el único pintor que gozó de cierta celebridad en los Estados Unidos. El grupo familiar formado por Eusebio, Plácido, Daniel e Ignacio Zuloaga tuvo su propia resonancia entre los coleccionistas, el gran público, e incluso algunos artistas americanos afanosos de aprender su oficio al lado de un maestro español (Querci, 2010; Stratton-Pruit, 2010; SuÁrez Zuloaga, 2010; Boone, 2010). A partir de mediados del siglo XX, el intercambio de exposiciones de arte promovió un mejor conocimiento cultural mutuo. Al mismo tiempo, la presentación de obras españolas ante grandes públicos y ante la crítica cualificada contribuyó a su mayor cotización en los mercados internacionales del arte contemporáneo (TuSELL, 2003).

$\mathrm{Si}$ interesa en los Estados Unidos el arte, también interesa la ciencia y la tecnología. No abundan en la historiografía española investigaciones relacionadas con estos temas, pero se ha publicado recientemente al menos un estudio breve sobre la demostración del autogiro de Juan de la Cierva en Nueva York (DE LA GuARDIA, 2000). 
Sería empeño iluso intentar abarcar en toda su riqueza temática el reflejo en el cine estadounidense de elementos culturales españoles: de personajes históricos e imaginarios, heroicos y míticos, historias reales y ficticias, costumbres, productos, y paisajes, todos los cuales podrían inspirar investigaciones históricas y científico-sociales. La economía de nuevo se impone, así que mencionamos sólo tres ejemplos recientes que han tratado desde diferentes perspectivas un mismo tema: la poderosa imagen cinematográfica de Carmen (ARAGÓN, 2005; FEENSTRA, 2005; VilChES, 2005).

Por último, aunque es difícil separar la propaganda política de las relaciones diplomáticas, la naturaleza misma de la propaganda implica el planteamiento de objetivos y el manejo de contenidos y medios que, por necesidad, han de basarse en el conocimiento de las condiciones sociales y culturales. De hecho, el grado de eficacia de la propaganda será determinado en gran medida por ese conocimiento. Un estudio reciente aborda el fascinante tema de las publicaciones periódicas españolas impresas en Estados Unidos entre 1936 y 1960 que fueron investigadas y controladas por el FBI (ORDAZ, 2001). Otro trabajo presenta un tema similar, al analizar las actitudes de algunos intelectuales estadounidenses ante la propaganda pro-republicana durante la guerra civil española (BERMEJILlo, 2004).

\section{LOS ESTADOS UNIDOS EN PERCEPCIONES ESPAÑOLAS}

Ha atraído la atención de numerosos historiadores españoles la evolución en España de las imágenes los Estados Unidos, no sólo por el interés intrínseco del tema, sino porque las formas de expresar dichas percepciones pueden ser muy reveladoras de las actitudes y valores culturales de distintos sectores de la propia sociedad española. Esta forma de enfocar la investigación resulta especialmente fructífera para estudiar determinados períodos críticos de la historia de uno u otro país, y sobre todo aquellos momentos cuando la tensión diplomática entre ambos hubiese hecho aflorar fuertes opiniones y controversias.

Varias investigaciones recientes analizan las actitudes y valoraciones españolas sobre los Estados Unidos, desde perspectivas generales, y por diversos períodos cronológicos. Durante los años de la independencia y consolidación de la nueva república entre 1776 y 1803 , predominaban las opiniones negativas (surgidas principalmente de la conciencia de la amenaza que suponía para los intereses españoles), pero también hubo claras manifestaciones de admiración del modelo político y social del nuevo país (HiLTON, 2008). La intervención estadounidense en la crisis colonial española entre 1895 y 1899 inclinó fuertemente el discurso de las clases dirigentes en sentido negativo, aunque los republicanos federalistas mantuvieron contra viento y marea su tradicional admiración por el modelo americano ${ }^{6}$.

${ }^{5}$ La bibliografía es abundante pero a título representativo véase SCHUMACHER - GIENOW-HeCHT, 2003, y, entre los autores españoles, NiÑo, 2009c.

${ }^{6}$ La abundancia de estudios sobre las imágenes de los Estados Unidos en el discurso público español durante este período aconseja remitir a los ensayos historiográficos de SANTAMARÍA - NARANJO, 1999, y HERNÁNDEZ SANDOICA, 2002. 
Ya en el siglo XX, el período entre las dos guerras mundiales cuenta con varios trabajos recientes. De nuevo se ha sometido a examen diversas opiniones españolas sobre el modelo político ofrecido por los Estados Unidos (NiÑo, 2009a). Por otra parte, se han dado a luz algunos resultados de investigaciones que analizan las opiniones vertidas en una amplia selección de periódicos españoles, representativos de diferentes líneas ideológicas, sobre el primer mandato de Franklin Delano Roosevelt. Un extenso repertorio bibliográfico de artículos publicados en la prensa española, sobre temas estadounidenses, documenta el grado de interés generado durante la segunda república española por el desarrollo del New Deal entre 1932 y 1936 (ARROYO - SAGREDO, 2001). Otros trabajos siguen la cobertura periodística española del mundo industrial y el sindicalismo en ese mismo período (ARROYO, 2001), y temas relacionados con la agricultura y el asociacionismo agrario (SAGREDO, $2001 \mathrm{y}$ 2006). También se ha analizado el tratamiento periodístico de las elecciones presidenciales estadounidenses de 1932 (SAGREDO, 2005), y las actitudes de la prensa católica española ante la política de Roosevelt (SAGREDO, 2004).

Ya comentamos que el inicio de la guerra fría ha sido tema predilecto de la historiografia española enfocada hacia las relaciones diplomáticas y militares. Sin embargo, novedosos estudios recientes han abierto nuevas líneas de investigación que empiezan a desentrañar la compleja madeja de conexiones entre la diplomacia, la propaganda política, la cooperación científica y tecnológica, y la promoción cultural (DELGADO, 2005; NiÑO, 2009b; LEÓN, 2008 y 2009). La opinión pública española sobre los Estados Unidos en la actualidad también está documentada y analizada (NoYA, 2003b).

Otro enfoque, del que podemos citar dos ejemplos recientes, es el estudio de las relaciones culturales a través de personajes históricos estadounidenses. Las imágenes de Benjamin Franklin en obras históricas españolas -favorables por regla general-pone de relieve cómo la propia historiografía sobre otro país es una forma de interacción cultural (HERNÁNDEZ, 2008). Un análisis de las imágenes periodísticas de Franklin Delano Roosevelt - una figura mucho más discutida - de nuevo subraya la importancia de los medios de comunicación en las relaciones culturales internacionales del siglo XX (ARROYO, 2005).

Un tipo de fuente especialmente sugerente, porque ofrece unas perspectivas y facetas interpretativas muy particulares, son los relatos de viaje y otros escritos de viajeros. Varias publicaciones recientes exponen y analizan las impresiones sobre los Estados Unidos de diversos grupos de viajeros españoles. Se trata de intelectuales y científicos, escritores y profesores, o personas dedicadas a las bellas artes o las artes escénicas, pero tienen en común que sus conexiones con los Estados Unidos abarcan el período de fines del siglo XIX y primer tercio del siglo XX. Enrique Dupuy de Lôme, Juan Valera, Julio Camba, Jorge Santayana, José Moreno Villa, y otros muchos meditaron sobre el carácter de los norteamericanos, sobre su organización social, sus valores, su potencialidad y expansión económicas, su capacidad de innovación tecnológica, su cultura política, las escuelas y universidades, las instituciones penitenciarias, los hospitales, la prensa, la opinión pública, el papel de las mujeres, y muchos más aspectos de un país en pleno auge (GARCÍA-MONTÓN, 2000a y 2002; GARCÍA MuÑOZ, 2008; FERNÁNDEZ, 2010). También han aparecido diversos trabajos recientes dedicados a las vivencias e impresiones de individuos concretos, como el exiliado Félix Mejía en 1824-1827 (SIMAL, 
2008), Ramón de la Sagra en 1835 (GARCíA-MonTóN, 2000b), y el filósofo Julián Marías en los años de 1950 (RALEY, 2002). Tampoco faltan percepciones más literarias, en las cuales las imágenes estadounidenses se ven tamizadas por la sensibilidad creativa de escritores como Vicente Blasco Ibañez (MIRA, 2004), Federico García Lorca (GARCÍA LÓPEZ, 2001, FERNÁNDEZ, 2010) y Carmen Martín Gaite (MARTín GAITE, 2005).

A lo largo del siglo XX y en lo que va del siglo XXI, diversas iniciativas privadas han sido concebidas como formas de exportar aspectos de la cultura estadounidense a España. Tres estudios recientes abordan temas bien diferentes: la colaboración en la formación de jóvenes científicas españolas del laboratorio Foster de la Residencia de Señoritas de Madrid (MAGAllón, 2007), la obra científico-cultural en España de la Fundación Ford (De SANTISTEBAN, 2009), y las actividades de la Iglesia Evangélica de Filadelfia entre los gitanos del Levante español (CORREAS, 2009). Ahora bien, a nivel de la conciencia popular, sin duda han tenido una influencia mucho mayor el cine y la televisión. Como espejos de dos caras (en cuanto a imágenes del "otro", y de uno mismo en los ojos del "otro"), se prestan a toda clase de estudios relacionados con procesos internacionales de intercambio cultural y el papel de España. Sin entrar en los guiones de las películas y programas de televisión, ni en sus mensajes ideológicos más o menos sutiles, la sociedad española (como la mayoría de las de occidente y buena parte del resto del mundo) quedó impactada por las imágenes de bienestar, de abundancia, de avances tecnológicos en los transportes, en las ciudades y en los hogares. El "sueño americano" se hizo visible en las pantallas, y queda mucho por estudiar sobre sus repercusiones culturales entre los españoles(GUERRA GÓMEZ, 2002). Por otra parte, importantes investigaciones recientes profundizan en la proyección internacional de la industria cinematográfica de los Estados Unidos, desentrañando las complejas interconexiones entre la cultura, la diplomacia y el comercio en las relaciones hispano-estadounidenses, durante la segunda guerra mundial y durante el quinquenio de 1950-1955 (LEÓN, 2006 y 2006).

Las percepciones del "otro" casi siempre vienen acompañadas por juicios de valor. Desde el nacimiento de los Estados Unidos en 1776, ha existido en España una tenue pero persistente corriente de opinión favorable hacia la "gran república". En el siglo XIX, la simpatía era una función de ideologías republicanas y demócratas minoritarias que mantenían posturas de oposición crítica hacia el régimen o el gobierno de turno en España. En tiempos más recientes, ejercen una fuerte atracción productos estadounidenses como los relacionados con la cultura popular o con la nueva cultura de los mundos profesionales y empresariales. Ahora bien, si en los Estados Unidos han perdurado durante largo tiempo las imágenes negativas de España, no se ha quedado atrás el antiamericanismo español. Por diversos motivos culturales e históricos, ha tendido a predominar entre los españoles una visión negativa de ese país, y así lo han reflejado varios estudios recientes (MARTín DE LA Guardia, 2003; Chislett, 2005; FernÁndeZ De Miguel, 2006). Tradicionalmente, el antiamericanismo español predominaba entre las clases dirigentes conservadoras, aunque se fue matizando esa postura a partir de mediados del siglo XX (FERNÁndEZ DE Miguel, 2009). Está demostrado que el tema del antiamericanismo de la opinión pública española actual está abierto a la discusión y admite el planteamiento de interesantes matices conceptuales (NOYA, 2003a). Sin embargo, sigue publicándose cier- 
to tipo de ensayo marcado por la pobreza documental y la superficialidad analítica, que desafortunadamente no hace sino repetir lugares comunes (SEREGNI, 2007).

La segunda guerra mundial lanzó definitivamente a los Estados Unidos hacia un papel de liderazgo, y la posterior polarización política del mundo hizo que sucesivos gobiernos estadounidenses asumieran la necesidad de contrarrestar el antiamericanismo por todos los medios posibles. Había que ganar simpatías y voluntades, convenciendo a los grupos políticamente activos de sociedades muy diversas sobre la superioridad del modelo político democrático abanderado por los Estados Unidos. La propaganda gubernamental estadounidense en España durante y después de la segunda guerra mundial era un aspecto significativo de las relaciones diplomáticas, pero como discurso público concebido para la persuasión, debía manejar con suma destreza muchos recursos culturales. En definitiva, el grado de éxito de la propaganda dependía hasta cierto punto del conocimiento y de la sensibilidad ante la cultura española (Pizarroso, 2000 y 2009; Delgado, 2009b). También se trataba de ejercer el llamado "poder blando" para promover el conocimiento de la cultura estadounidense, desde la confianza en su capacidad de atracción y de persuasión. Consiguientemente, se desarrolló una importante diplomacia cultural en muchos países, entre los cuales se contaba España. Una de las iniciativas gubernamentales de mayor envergadura fue la creación del Programa Fulbright, que no sólo requería negociaciones diplomáticas para la realización de intercambios científico-culturales, sino que escondía en sus entresijos tensas y complicadas historias institucionales, académicas, propagandísticas, de poder político, de intereses económicos, y por supuesto de aspiraciones profesionales y vivencias personales. En la historiografía europea, se han producido numerosas investigaciones sobre las actividades del Programa Fulbright en los diversos países, por considerar que es un tema que se presta especialmente bien a los nuevos enfoques de la historia de las relaciones culturales internacionales. En el caso español varios trabajos han venido a llenar un importante vacío, ofreciendo investigaciones sobre el desarrollo general del programa en España (DELGADO, 2009a), y sobre los becarios, tanto los estadounidenses en España como los españoles en los Estados Unidos (Rivière, 2002; Metroscopia, 2009). Uno de los objetivos declarados del Programa Fulbright y de otras iniciativas gubernamentales y privadas ha sido la promoción de la enseñanza de la cultura estadounidense en universidades españolas. Al principio, chocó con el problema de la falta de conocimientos de la lengua inglesa y con las rigideces estructurales en la organización de la enseñanza superior en España, y aun hoy los estudios norteamericanos se enfrentan a toda clase de dificultades. La historia crítica de la literatura es la disciplina más cultivada, pero aunque se publica mucho sobre temas literarios estadounidenses, no abundan investigaciones cuya temática establezca algún tipo de conexión cultural con España. A título de ejemplo, dos estudios indagan sobre el contexto político que afectó la recepción en España de obras de Arthur Miller en los años de 1950 (ESPEJO, 2002 y 2004). Sobre la enseñanza de la literatura norteamericana en España se publicaron las aportaciones a una mesa redonda (GUIJARRO - FríAS - MANUEL, 2004). Los inicios de los estudios norteamericanos en la Universidad de Salamanca han sido objeto de una investigación doctoral, en la cual se aborda la relación entre 
ese campo de estudios académicos y la diplomacia cultural estadounidense durante la guerra fría (RODRÍGUEZ JiMÉNEZ, 2008 y 2010)7 2

\section{PRESENTACIÓN DEL DOSSIER "ESPAÑA Y LOS ESTADOS UNIDOS: INTERPRETACIONES CULTURALES CONTEMPORÁNEAS”}

Como hemos comprobado al rendir cuentas de la historiografía española del decenio pasado, son múltiples los aspectos de la historia de las relaciones culturales hispano-estadounidenses que han inspirado a los investigadores. Sin embargo, falta mucho por hacer en este campo, porque es evidente que todavía permanecen sin explorar, o al menos inéditos, numerosos temas. Las aportaciones de los artículos del presente dossier vienen, pues, a contribuir a una línea de investigación relativamente nueva.

Como autor de obras de reconocido valor sobre la historia y la cultura españolas, Richard L. Kagan ha acreditado cumplidamente no sólo sus conocimientos sino su sensibilidad para afrontar las complejidades de temas que implican el entrecruzamiento de culturas diferentes. En su contribución a este dossier, examina la fascinación que se desarrolló en los Estados Unidos entre 1890 y 1930 por todo lo español. El período histórico elegido es bien interesante puesto que coincidieron en ese período, por un lado, la crisis colonial española definitiva en América y, por otro lado, el ascenso de los Estados Unidos al estatus de gran potencia. Según este autor, tanto los arquitectos como los coleccionistas de arte y otros objetos de interés cultural en los Estados Unidos se vieron presos de una auténtica "locura" por imitar edificaciones o poseer cuadros y objetos artísticos españoles. Se dio, además, la circunstancia de que no se quedó en una obsesión compartida por unos pocos privilegiados, sino que fue también un período histórico durante el cual se hicieron grandes esfuerzos por difundir y cultivar el interés por la cultura española entre un público mayor. Este objetivo se persiguió a través del establecimiento de instituciones, dotadas de adecuados recursos económicos, que se dedicarían a la conservación, al estudio y a la exposición de obras de arte y objetos de valor cultural procedentes de España. Por último, el autor no esconde la existencia también de deseos de apropiación e incluso rapiña de culturas ajenas, y de faltas de tacto que reflejaban el poderío de los Estados Unidos y la agresividad de su expansionismo. Richard L. Kagan es profesor del Departamento de Historia de la Universidad Johns Hopkins, de Baltimore, en el estado de Maryland, y es autor de numerosos estudios sobre la historia de España, y las relaciones culturales hispano-estadounidenses.

El Guernica de Picasso es sin duda una obra maestra del arte moderno, y es incuestionable su enorme influencia sobre los artistas del expresionismo abstracto, tanto en los Estados Unidos como en otros países. En particular, como muestra el estudio de María Dolores Jiménez, durante los años de 1940, la obra fue una fuente

${ }^{7}$ Sobre la enseñanza de la historia de los Estados Unidos en universidades españolas véase HiLton, 2007. La experiencia española tiene sus peculiaridades, pero también comparte muchas de las características de la evolución del estudio de la historia estadounidense en otras universidades europeas desde la II Guerra Mundial. Para este tema véase Hilton - Van Minnen, 2007, pp. 7-43. 
de inspiración para los artistas de la Escuela de Nueva York, tanto por sus características propiamente creativas y estéticas, como por su expresión de la crisis moral que padecieron Picasso y otros muchos afectados por las guerras de su tiempo. El Guernica se convertiría en una obra icónica del siglo XX, un símbolo y un ejemplo de la capacidad de compromiso político e ideológico que podía asumir y expresar cualquier artista que quisiera reflejar a través de su arte su preocupación por las injusticias sociales de su tiempo. M. Dolores Jiménez Blanco es profesora de Historia del Arte Contemporáneo de la Universidad Complutense de Madrid, y es autora (y co-autora con Cindy Mack) de varias publicaciones sobre diversos aspectos del arte de los Estados Unidos y el coleccionismo de obras artísticas españolas en aquel país.

Aparte del interés intrínseco del tema y el período histórico que trata, la contribución al dossier de Javier Maestro Bäcksbacka y Antonia Sagredo Santos presenta varias originalidades. Por un lado, sus fuentes no son habituales en la historiografía española. Basan su estudio en la prensa publicada en los Estados Unidos, procedente de un archivo particular, y estas fuentes representan el armazón sobre el que se teje la conexión entre los temas analizados. Por otro lado, comentan muy diversos cauces por los cuales discurrían las relaciones culturales hispano-estadounidenses, al margen de las políticas gubernamentales: intercambios de ideas, productos y personas, especialmente estudiantes; las actividades de interacción cultural realizadas en ambos países por particulares, tanto españoles como norteamericanos; la publicación en los Estados Unidos de libros referentes a temas españoles; y algunas noticias periodísticas sobre el cine estadounidense en España. Javier Maestro Bäcksbacka es profesor de Historia de la Comunicación Social de la Universidad Complutense, y es autor de varios trabajos sobre el pensamiento científico decimonónico entre los intelectuales estadounidenses y españoles, y sobre la esclavitud y el racismo en los Estados Unidos. Antonia Sagredo Santos es profesora de Filología Inglesa en la Universidad Nacional de Educación a Distancia, y es autora de numerosos estudios sobre la historia de los Estados Unidos, destacando su dedicación a temas relacionados con el New Deal de Franklin Delano Roosevelt, el mundo agrario de los años de 1930, y las mujeres norteamericanas. Además, es, con M. Luz Arroyo Vázquez, autora de los dos libros de texto de la U.N.E.D. para los estudiantes de la historia de los Estados Unidos.

Las relaciones artísticas entre España y los Estados Unidos se desvelan como campo abonado para la investigación histórica. La presencia del arte y de los artistas españoles en los Estados Unidos cuenta ya con cierto peso historiográfico, puesto que la mayoría de los estudios publicados en España se refieren a las exposiciones, las influencias y el coleccionismo del arte español, o a los viajes de artistas españoles, en los Estados Unidos. En cambio, el caso inverso no es tan aparente. En eso estriba, en parte, la originalidad de la aportación de Carmen Bernárdez Sanchís a este dossier, porque contribuye al conocimiento de la recepción en España de una faceta importante de la cultura estadounidense. Además, revela y analiza el valor intelectual y social de la labor de Aguilera Cerni como crítico de arte innovador, centrándose especialmente en su autoría de dos obras (publicadas en 1955 y 1957) que pre- 
sentaban ante el público español creaciones artísticas estadounidenses que resultaban inéditas y sorprendentes en la España franquista de los años de 1950. Carmen Bernárdez Sanchís es profesora de Historia del Arte Contemporánea en la Universidad Complutense de Madrid, y es autora de diversos estudios sobre las relaciones artísticas hispano-estadounidenses, y en especial sobre la recepción en España de teorías, exposiciones, información y movimientos estéticos relacionados con el arte estadounidense.

La guerra fría cultural reflejó un enfrentamiento ideológico mundial. Por su larga duración y sus múltiples formas de expresión, repercutió en todas las sociedades occidentales. Una de las iniciativas emblemáticas de la diplomacia cultural estadounidense, con muchos apoyos de organizaciones privadas, fue el esfuerzo por promover el estudio de la cultura estadounidense, mediante la exportación de un modelo interdisciplinario de enseñanza superior denominado en España como "estudios norteamericanos", a pesar de las dificultades teóricas y repetidas crisis de identidad internas que padecía ese campo de estudio en los Estados Unidos. La aportación de Francisco J. Rodríguez Jiménez a este dossier analiza algunas de las controversias surgidas en torno a la promoción de la cultura estadounidense en otras sociedades, así como su función en la diplomacia y en la formación universitaria de elites sociales occidentales. En 2009 Francisco J. Rodríguez Jiménez defendió en la Universidad de Salamanca su tesis doctoral, co-dirigida por Josefina Cuesta y Lorenzo Delgado. Sus publicaciones relacionadas con el tema del dossier están recogidas en esta introducción y en su propio artículo, y otras están en prensa. Actualmente, es investigador visitante en la Universidad de Georgetown, Washington, D.C., tras obtener una beca Fulbright en un concurso competitivo internacional.

La historia atlántica es un enfoque que, a ambos lados del Atlántico, tiene sus defensores, pero también tiene muchos detractores. Han surgido fuertes recelos académicos, a veces expresados con lúcidos argumentos, pero a menudo inspirados en posiciones ideológicas, a causa de las relaciones del "atlantismo" con la expansión colonial europea, con la trata de esclavos, con el "occidentalismo", y con ciertos enfoques diplomáticos estadounidenses. La controversia está servida y continuará, de modo que el ensayo historiográfico que ofrece Carmen de la Guardia Herrero resume oportunamente las contribuciones recientes de algunos de los historiadores estadounidenses quienes representan y definen este enfoque. Carmen de la Guardia es profesora de Historia Contemporánea en la Universidad Autónoma de Madrid, y es autora de importantes trabajos que reflejan su especial dedicación a la independencia de los Estados Unidos, su temprana expansión, y diversos aspectos de su sistema político.

\section{CONCLUSIONES}

El balance historiográfico realizado en el estudio introductorio y los artículos que forman el dossier demuestran la creciente apertura de la publicística española hacia la historia de otros países y la conexión de los investigadores españoles con la comunidad científica internacional mediante su interés por participar en los debates historiográficos 
actuales. Al ofrecer aportaciones sobre diversos aspectos de la historia de las relaciones culturales entre España y los Estados Unidos en el siglo XX, los artículos reunidos aquí contribuyen a ensanchar los nuevos horizontes del estudio de las relaciones internacionales.

Para ello se requiere una renovación conceptual y metodológica que permita pensar en el valor de muy variados tipos de fuentes primarias como ponen de manifiesto los artículos de este dossier. Es en este aspecto donde hacen su mayor contribución Javier Maestro y Antonia Sagredo, al utilizar sus fuentes periodísticas estadounidenses como eje principal de su análisis, para establecer conexiones entre las noticias relacionadas con la cultura española que se juzgaban de interés para el público estadounidense.

En el sistema político internacional, los estados reconocen fronteras territoriales y límites jurisdiccionales, y los gobierno promueven las relaciones culturales para sus fines diplomáticos. Sin olvidar esta realidad, este dossier ofrece también ejemplos de cómo muy diversos actores sociales (solos o en grupos, redes y organizaciones) pueden desafiar las barreras políticas, con el fin de favorecer o participar en actividades de entrecruzamiento cultural. Además, los autores abordan temas poco desarrollados hasta la fecha en la historiografía española sobre las relaciones bilaterales entre España y los Estados Unidos en el siglo XX. Mientras que Richard Kagan estudia algunos aspectos del hispanismo en los Estados Unidos, Francisco Rodríguez analiza la promoción de los estudios 'norteamericanos' con ejemplos del caso español. Ambos autores examinan estas relaciones culturales en contextos ideológicos y políticos más amplios, y también tienen en común la primacía que dan al papel del poderío ejercido por los estadounidenses. Por su parte, Lola Jiménez Blanco analiza el arte español en los Estados Unidos, mientras que Carmen Bernárdez examina el arte estadounidense en España. Ambas subrayan la importancia histórica de estos intercambios culturales para el mejor conocimiento mutuo de estas dos sociedades. En conclusión, la historia de la interacción cultural entre España y los Estados Unidos se desvela como un aspecto fundamental de las relaciones entre los dos países a lo largo del siglo XX.

\section{REFERENCIAS BIBLIOGRÁFICAS}

\section{ALONSO ZALDÍvAR, Carlos}

2003 Miradas torcidas. Percepciones mutuas entre España y Estados Unidos. Documento de trabajo /Working paper 2003/16. Madrid. Real Instituto Elcano de Estudios Internacionales y Estratégicos. Septiembre $1^{\circ}$. En $\mathrm{http} /$ www.realinstitutoelcano.org/documentos

Aragón, Agustín, Jr.

2005 "Los amores de Carmen". Archivos de la Filmoteca. Madrid. n 51, pp. 94-101.

Arroyo VÁzQuez, M. LuZ

2001 Industria y trabajo en el New Deal de Franklin D. Roosevelt a través de la prensa española, 1932-1936. Tesis doctoral. Madrid. Universidad Complutense. 
2005 "The Image of Franklin Delano Roosevelt in the Spanish Press". En LÓPEZ LIQUETE et al. (eds.), pp. 39-54.

Arroyo VÁzquez, M. Luz, - Sagredo Santos, Antonia

2001 La segunda república y los Estados Unidos: bibliografía de artículos periodísticos españoles, 1932-1936. Madrid. Fundación Universitaria Española.

BERMEJILlo IBÁÑEZ, Ana

2004 "Too Many Committees: reacciones de algunos intelectuales americanos ante la propaganda filo-republicana en los últimos años 30". Aportes. Revista de Historia Contemporánea. Madrid. nº 56, pp. 18-26.

Bigatel, Bridget,

2005 "19th Century American Women Travelling in Spain. Unique Vistas from a Well-Trodden Path". En LóPEZ LiQueTE et al. (eds.), pp. 61-68.

BoOne, M. Elizabeth

2010 "Choosing Zuloaga. American Painters, Spanish Teachers, and Gender Conflict in the Early Twentieth Century". En PAYNe, et al. (eds.), pp. 189-214.

Boyd, Carolyn P.

2000 "El hispanismo norteamericano y la historiografía contemporánea de España en la dictadura franquista". Historia Contemporánea. VitoriaBilbao. $n^{\circ}$ 20, pp. 103-116.

2002 "La imagen de España y los españoles en los Estados Unidos de América". Investigaciones Históricas. Época moderna y contemporánea. Valladolid. $\mathrm{n}^{\mathrm{o}}$ 22, pp. 317-328.

CABALler Dondarza, Mercedes

2007 La narrativa española en la prensa estadounidense. Hallazgo, promoción, publicación y crítica, 1875-1900. Madrid. Iberoamericana Vervuert.

CAstillo, Francisco Javier

2002 "Sobre estereotipos, imágenes parciales y retratos imposiblemente planos. La noción de España en la Norteamérica del primer tercio del siglo XIX”. Revista Canaria de Estudios Ingleses. La Laguna. n 44, pp. 301-304.

CORREAS REDONDO, Francisco

2009 "La Iglesia Evangélica de Filadelfia y los gitanos". Anales de Historia Contemporánea. Murcia. $\mathrm{n}^{\mathrm{o}}$ 25, pp. 289-298.

CRIADO, M $\mathrm{M}^{\mathrm{a}}$ Jesús

2004 "La lengua española en los Estados Unidos. Presente y perspectivas". Cuadernos de la Escuela Diplomática. Madrid. n²6, pp. 61-80.

Chislett, William

2005a España y Estados Unidos. En busca del redescubrimiento mutuo. Madrid. Ariel.

2005b "El antiamericanismo en España. El peso de la historia". Documento de trabajo del Real Instituto Elcano, 15 noviembre. En http.//www.realinstitutoelcano.org/documentos/228/228_Chislett.pdf 
De la Guardia, Carmen

2008 "La Corte de Madrid y la virtud republicana: Los escritos de Sarah Livingston Jay (1779-1784)”. En SÁnCHEZ MonTAÑÉs, et al. (eds.), pp. 259-297.

De la Guardia Salvetti, Fernando

2000 "La historia vivida. El autogiro de Juan de la Cierva en la ciudad de los rascacielos". Revista de Historia Naval. Madrid. vol. XVIII: 69, pp. 93-96.

De Santisteban Fernández, Fabiola

2009 "El desembarco de la Fundación Ford en España". Ayer. Madrid. vol. 75: 3, pp. 159-191.

DELGADO, Lorenzo

2003 "Las relaciones culturales entre España y Estados Unidos. De la Guerra Mundial a los Pactos de 1953". Cuadernos de Historia Contemporánea. Madrid. $n^{\circ} 25$, pp. 35-59.

2005 "Cooperación cultural y científica en clave política. Crear un clima de opinión favorable para las bases U.S.A. en España". En Delgado ELIZALDE PÉREZ-GRUESO (eds.), pp. 207-245.

2009a Viento de poniente. El programa Fulbright en España. Madrid. LID Editorial Empresarial. Fulbright España - MAEC - AECID.

2009b "La maquinaria de la persuasión. Política informativa y cultural de Estados Unidos hacia España". Ayer. Madrid. vol. 75: 3, pp. 97-132.

Delgado, Lorenzo - Elizalde PÉrez-Grueso, Ma Dolores (eds.)

2005 España y Estados Unidos en el siglo XX. Madrid. CSIC.

ESPEJO ROMERO, Ramón

2002 “Death of a Salesman, de Arthur Miller, en España durante los años 50”. Atlantis. AEDEAN. vol. XXIV: 1, pp. 85-107.

2004 "El estreno de 'The Crucible' en España y su fallido intento de despolitización". En GuiJarro, Juan - EsPejo Romero, Ramón (eds.). Arthur Miller: Visiones desde el nuevo milenio. Valencia. Universitat de Valéncia, pp. 135-146.

FABER, Sebastian - MARTínEZ-CARAZO, Cristina (eds.)

2009 Contra el olvido. El exilio español en Estados Unidos. Alcalá. Universidad de Alcalá.

FEenstra, Pietsie

2005 "Mitos españoles y cuerpos exóticos. Carmen Jones (1954) y Carmen la Hip Hopera (2001)". Archivos de la Filmoteca. Madrid. n 51, pp. 84-93.

FERNÁNDEZ, James D.

2005 "La ley de Longfellow. El lugar de Hispanoamérica y España en el hispanismo estadounidense". En Delgado - Elizalde PÉrez-Grueso (eds.), pp. 95-112.

2010 "Poets, Peasants, Painters, Professors and Performers in Nueva York". En PAYNE, et al. (eds.), pp. 47-60. 
FERNÁNDEZ DE Miguel, Daniel

2006 "El antiamericanismo en la España del primer franquismo (1939-1953): el Ejército, la Iglesia y Falange frente a Estados Unidos". Ayer. Madrid. $n^{\mathrm{o}}$ 62: 2, pp. 257-282.

2009 "La erosión del antiamericanismo conservador durante el franquismo". Ayer. Madrid. no 75: 3, pp. 193-221.

FERnÁndeZ FERnÁNDEZ, Xosé

2003 El arquitecto norteamericano Thomas Jefferson (1743-1826) y su relación con España. A Coruña. Universidad de A Coruña.

Flys, Carmen - CRUZ CABRERA, Juan (eds.)

2001 El Nuevo Horizonte. España-Estados Unidos. El legado de 1848 y 1898 frente al Nuevo Milenio. Alcalá de Henares. Universidad de Alcalá.

GARCÍA LÓPEZ, David

2001 "El rascacielos americano en 'Poeta en Nueva York' de García Lorca". Goya. Madrid. n' 280, pp. 30-36.

GARCía MuÑOZ, César

2008 Historia de un estereotipo. Intelectuales españoles en Estados Unidos (1885-1936). San Lorenzo de El Escorial. Langre.

GARCÍA-MONTÓN, Ma Isabel

2000a "Agentes de una aproximación cultural. Viajeros españoles en los Estados Unidos tras la guerra finisecular". En Travelling Across Cultures/Viaxes interculturais. The Twentieth Century American Experience. Santiago de Compostela. Universidad de Santiago de Compostela, pp. 237-249.

2000b "Notas sobre el viaje de Ramón de la Sagra a Estados Unidos". En Fontela, Concha - SiLVE, Manuel (eds.). Galicia-Cuba. Un patrimonio cultural de referencias y confluencias. Sada-A Coruña. Ediciós do Castro, pp. 265-277.

2002 Viaje a la modernidad. La visión de los Estados Unidos en la España finisecular. Madrid. Verbum.

GARCÍA-MonTÓN, Ma Isabel - García-Romeral, Carlos

2000 "Viajeros americanos en Andalucía durante los siglos XIX y XX". Revista Complutense de Historia de América. Madrid. n 26, pp. 261-280.

GIEST, David

2001 "El Hispanismo que viene. Estados Unidos y Canadá". Arbor. Madrid. vol. CLXVIII: 664, pp. 493-511.

GONZÁLEZ LÓPEZ, Emilio

2005 El paso por Galicia de dos futuros presidentes de EE.UU.: John Adams y su hijo John Quincy Adams. Trifolium. El Taller de Juan.

GuERra GómEZ, Amparo

2002 "Sentir la utopía. Cine e imágenes televisivas del American Dream". En Rueda, José Carlos - Vidal, José (eds.). Cine, Sociedad y Cultura. Madrid. Universidad Complutense de Madrid, pp. 97-110. 
Guijarro, Juan I. - FríAs, María - Manuel, Carme

2004 "Mesa Redonda: la enseñanza de la literatura norteamericana en España". En Celadd, Antonio - Pastor, Daniel - Pardo, Pedro J. (eds.) Actas del XXVII Congreso Internacional de AEDEAN. Salamanca. Ambos Mundos. Universidad de Salamanca. CD Rom.

HERNÁNDEZ RUIGÓMEZ, Almudena

2008 "Benjamín Franklin: la visión histórica española". En SÁNCHEZ MONTAÑÉs, et al. (eds.), pp. 297-316.

HERNÁNDEZ SANDOICA, Elena

2002 "La historiografía más reciente sobre el 98". Iberoamericana. América Latina-España-Portugal. Madrid-Frankfurt. vol. II: 5, pp. 213-222.

HitTon, Sylvia L.

1994 "American Studies in Spain: Recent Trends". American Studies International. Washington, D.C. vol. XXXII: 1, pp. 41-69.

2007 "The Study of U.S. History in Spain". En Van Minnen, Hitton, (eds.), pp. 231-252.

2008 "Un pueblo que aumentará la pérdida de vista'. Tempranas impresiones españolas sobre los Estados Unidos"'. En SÁNCHEZ MonTaÑés, et al. (eds.), pp. 241-264.

Hilton, Sylvia L. - Van Minnen, Cornelis

2007 "The Academic Study of U.S. History in Europe". En Van MinNEN Hilton (eds.), pp. 7-43.

ISBELL, Paul

2001 "Excepcionalidad española y excepcionalismo estadounidense. Raíces de desencuentros y reencuentros". En Flys - CrUZ CABRERA (eds.), pp. 47-54.

JACKSON, Gabriel

2001 "Concerning the Spanish Civil War and American Culture". En Flys CRuz CABrera (eds.), pp. 55-67.

JiMÉnEZ-BlANCO, María Dolores

2010 "Spanish Art and American Collections". En PAYNE, et al. (eds.), pp. 61-80. KAGAN, Richard L.

2007 "Yankees in the Prado: A Historiographical Overview". Boletín del Museo del Prado. Madrid. vol. XXV: 43, pp. 32-45.

LASAGABASTER, David

2006 Las lenguas de la diáspora vasca en el Oeste de los Estados Unidos. Bilbao/Iruña. Lete. 2006.

LeCuOna Prats, Emilio

2006 "El elemento hispano en la configuración del sistema jurídico de los Estados Unidos de América: 'mixed jurisdiction' en Luisiana (18031825)". Anuario de Historia del Derecho Español. Madrid. n 76 , pp. 645-666. 
LeÓn Aguinaga, Pablo

2006a "El cine norteamericano en España. Las negociaciones para su importación, 1950-1955". Hispania. Madrid. vol. LXVI: 222, pp. 277-318.

2006b "El comercio cinematográfico como instrumento de la acción norteamericana en España durante la Segunda Guerra Mundial”. Cuadernos de Historia Contemporánea. Madrid. no 28, pp. 303-322.

2008 El cine norteamericano y la España franquista, 1939-1960: relaciones internacionales, comercio y propaganda. Tesis doctoral. Madrid. Universidad Complutense.

2009 "Los canales de difusión del mensaje norteamericano en España, 19451960". Ayer. Madrid. no 75: 3, pp. 133-158.

LóPEZ LiQuete, $\mathrm{M}^{\mathrm{a}}$ Felisa, et al. (eds.)

2005 American Mirrors. (Self) Reflections and (Self) Distortions. VitoriaGasteiz. Universidad del País Vasco.

LÓPEZ MORALES, Humberto (ed.)

2009 Enciclopedia del español en los Estados Unidos. Anuario del Instituto Cervantes 2008. Alcalá de Henares. Santillana, Instituto Cervantes.

LÓPEz Mozo, Jerónimo

2006 "El teatro español en la universidad de Estados Unidos". Cuadernos Hispanoamericanos. Madrid. n 676, pp. 105-110.

MAESTRO, Javier

2001 "The Late Nineteenth-Century Scientific Impact on Spanish and American Intellectuals (1875-1898)". REDEN. Revista de Estudios Norteamericanos. Alcalá de Henares. no 21-22, pp. 125-142.

Magallón PoRTOlÉs, Carmen

2007 "El laboratorio Foster de la Residencia de Señoritas. Las relaciones de la JAE con el International Institute for Girls in Spain, y la formación de las jóvenes científicas españolas". Asclepio. Madrid. n LIX: 2, pp. 37-62.

MARTÍN DE LA GUARDIA, Ricardo

2003 "Las raíces del antiamericanismo español”. El Noticiero de las Ideas. Madrid. no 15, pp. 22-30.

Martín Gaite, Carmen

2005 Visión de Nueva York. Madrid. Siruela-Círculo de Lectores.

Martínez Ruiz, María José

2009 "La diplomacia española y estadounidense y su relación con el comercio de antigüedades en la primera mitad del siglo XX". Goya. Madrid. no 329, pp. 328-341.

Metroscopia, Estudios Sociales y de Opinión

2009 Estudio sociológico sobre los exbecarios del Programa Fulbright en España, Septiembre 2007. Madrid. LID Editorial Empresarial, Fulbright España, AECID.

MirA, Joan F.

2004 La prodigiosa historia de Vicente Blasco Ibáñez. Alzira. Algar. 
NIÑO, Antonio

2005 "Las relaciones culturales como punto de reencuentro hispano-estadounidense". En Delgado - Elizalde PÉrez-Grueso (eds.), pp. 57-94.

2007 "El exilio intelectual republicano en los Estados Unidos", Cuadernos de Historia Contemporánea. Madrid. Número extraordinario, pp. 229-244.

2009a "Miradas españolas al modelo norteamericano en el período de entreguerras". En FORCADELL, Carlos (ed.). Razones de historiador. Magisterio y presencia de Juan José Carreras. Zaragoza. Institución Fernando el Católico, pp. 405-420.

2009b "Dossier. La ofensiva cultural norteamericana durante la Guerra Fría. Presentación". Ayer. Madrid. no 75: 3, pp. 13-23.

2009c "Uso y abuso de las relaciones culturales en la política internacional".

NoYA, Javier Ayer. Madrid. no 75: 3, pp. 25-61.

2003a “¿Antiamericanismo, antihegemonismo o antiunilateralismo?” Madrid. Real Instituto Elcano. Documento de trabajo/ Working Paper, 16 de julio. En http://www.realinstitutoelcano.org/analisis/318/ARIANTIAMER.pdf

2003b "La imagen de Estados Unidos en España. Resultados del Barómetro del Real Instituto Elcano". Madrid. Real Instituto Elcano. Documento de trabajo/ Working Paper, 21 de julio. En http://www.realinstitutoelcano.org/documento

NoyA, Javier - RoDRíguEZ, Beatriz - RuIz JimÉnEZ, Antonia María

2008 La imagen de España en Estados Unidos. Madrid. Real Instituto Elcano. Documento de trabajo/ Working paper $n^{\circ} 44.27$ de octubre. En http://www.realinstitutoelcano.org/documento

Ordaz Romay, María Ángeles

2001 "Control y ambigüedad. Las investigaciones del FBI sobre las publicaciones periódicas españolas impresas en Estados Unidos (1936-1960)". En Flys - Cruz CABrera (eds.), pp. 141-151.

2006 "Las Sociedades Hispanas Confederadas en archivos del FBI. (Emigración y exilio español de 1936 a 1975 en EE.UU.)". Revista Complutense de Historia de América. Madrid. no 32, pp. 227-247.

OrTIz GarcíA, Carmen

2007 "Raíces hispánicas y culturas americanas. Folkloristas de Norteamérica en el Centro de Estudios Históricos". Revista de Indias. Madrid. vol. LXVII. no 239, pp. 125-162

OTERO, Jaime

2004 "La lengua española en la universidad estadounidense". Cuadernos de la Escuela Diplomática. Madrid. n 26, pp. 81-88.

Paredes Manzanero, Matilde, et al.

1996 American Studies Bibliography Published in Spain, 1994-1996. Madrid. S.A.A.S., Fulbright Commission, U.S.I.S. 
PAYNe, Stanley G.

2003 "Los Estados Unidos y España. Percepciones, imágenes e intereses". Cuadernos de Historia Contemporánea. Madrid. 25, pp. 155-167.

2010 "The Reencounter between the United States and Spain after 1898". En PAYNE, et al. (eds.), pp. 11-24.

PAYNE, Stanley G., et al. (eds.)

2010 When Spain Fascinated America. Madrid. Fundación Zuloaga.

PizARroso Quintero, Alejandro

2000 "La propaganda norteamericana en España en la Segunda Guerra Mundial". En EsPeJo, Carmen (ed.). Propaganda impresa y construcción del estado moderno y contemporáneo. Sevilla. Alfar. pp. 73-101.

2009 Diplomáticos, propagandistas y espías. Estados Unidos y España en la

QUERCI, Eugenia Segunda Guerra Mundial: información y propaganda. Madrid. C.S.I.C.

2010 "Zuloaga and the [sic] Spanish Culture from Europe to the United

RALEY, Harold States". En PAYNE, et al. (eds.), pp. 119-152.

2002 “Julián Marías y los Estados Unidos en escorzo". Revista de Occidente. Madrid. $n^{\circ}$ 252, pp. 13-23.

RiviÈRE GÓMEZ, Aurora

2002 "Angloamericanismo español e Hispanismo norteamericano. Los 'Fulbright' estadounidenses en la etapa franquista (1959-1975)". Revista Española de Estudios Norteamericanos. Alcalá. vol. XIII. n ${ }^{\circ}$ 23-24, pp. 57-84.

RODRÍGUEZ JIMÉNEZ, Francisco Javier

2007 'Haciendo amigos': intercambios educativos hispano-estadounidenses en clave política, 1959-1969". Studia Historica. Historia Contemporánea. Salamanca. ${ }^{\circ} 25$, pp. 339-362.

2008 "¿Ideología, Educación o Propaganda? Promoción y difusión de los Estudios Norteamericanos en Salamanca, 1939-59". Studia Historica. Historia Contemporánea. Salamanca. $\mathrm{n}^{\circ}$ 26, pp. 243-271.

2010 ¿Armas de convicción masiva? American Studies durante la Guerra Fría: el caso español. Tesis doctoral. Salamanca. Universidad de Salamanca. Colección Vítor $n^{\circ}$ 268. [CD-Books]

RuEda HeRnanZ, Germán

2009 "Intelectuales y emigrantes españoles en Estados Unidos en torno a la Guerra Civil". En Avilés, Juan (ed.), Historia, política y cultura. Homenaje a Javier Tusell. Madrid. U.N.E.D., pp. 285-318.

SABALETE Gil, Carmen

2002 "Las crucifixiones de Bacon y Barceló". Espacio, Tiempo y Forma. Serie VII, Historia del Arte. Madrid. no 15, pp. 365-404.

SAGREDO SANTOS, Antonia

2001 Franklin D. Roosevelt y la problemática agraria: su eco en la prensa española (1932-1936). Tesis doctoral. Madrid. Universidad Complutense. 
2004 "El discurso de la prensa católica ante el New Deal estadounidense. El Debate, 1932-1936". Historia Sacra. Madrid. vol. LVI. no 114, pp. 687-708.

2005 "El discurso de la prensa madrileña de la Segunda República ante las elecciones presidenciales estadounidenses de 1932". Historia y Comunicación Social. Madrid. $\mathrm{n}^{\circ}$ 10, pp. 201-219.

2006 "El auge del asociacionismo en la agricultura americana del New Deal y su proyección en la prensa española de los años 30". Historia y Comunicación Social. Madrid. nº 11, pp. 147-171.

SALVADOR OlivÁn, José Antonio

2002 "Formación en recuperación de información: análisis de los cursos y asignaturas en las escuelas de biblioteconomía y documentación de Norteamérica y España”. Revista Internacional de Ciencias de la Información. Madrid. $\mathrm{n}^{\circ}$ 25, pp. 189-215.

SÁNCHEZ MANTERO, Rafael

1998a "La imagen de España en los Estados Unidos". Revista de Occidente. Madrid. $n^{\circ}$ 202-203, pp. 294-309.

1998b "La mirada americana. La evolución de un estereotipo". Ayer. Madrid. no 31, pp. 229-236.

2001 "Viajeros y diplomáticos en el reinado de Fernando VII. El descubrimiento de España por los americanos". Ayer. Madrid. no 41, pp. 141160.

SÁNCHEZ MonTAÑés, Emma, et al. (eds.)

2008 Norteamérica a finales del siglo XVIII: España y los Estados Unidos. Madrid. Marcial Pons - Fundación Consejo España-Estados Unidos.

SANTAMARÍa, Antonio - NARANJo, Consuelo

1999 "El 98 en América. Últimos resultados y tendencias recientes de la investigación". Revista de Indias. Madrid. vol. LIX. n 215 (eneroabril), pp. 203-274. http://dx.doi.org/10.3989/revindias.1999.i215.745

SCHUMACHER, Frank, - GienOw-Hecht, Jessica

2003 Culture and International History. New York. Berghahn Press.

SEREGNI, Alessandro

2007 El antiamericanismo español. Madrid. Síntesis.

SiMAL, Juan Luis

2008 "En la cuna de la libertad. Félix Mejía, un exiliado español en Estados Unidos, 1824-1827". Historia y Política. Ideas, procesos y movimientos sociales. Madrid. n 20, pp. 265-291.

Stratton-Pruit, Suzanne L.

2010 "Ignacio Zuloaga in America. 1909-1925". En PAYNE, et al. (eds.), pp. 153-188.

SuÁReZ Zuloaga, Ignacio

2010 “A Spanish Saga of International Artists”. En PAYNE, et al. (eds.), pp. 81-118. 
Tusell García, Genoveva

2003 "La internacionalización del arte abstracto español. El intercambio de exposiciones con los Estados Unidos (1950-1964)". Espacio, Tiempo y Forma. Serie VII, Historia de Arte. Madrid. n 16, pp. 223-232.

VALERo GARCÉs, Carmen

2002 "Discursos del uno para con el otro entre los que están y los que llegan a España y Estados Unidos. Encuesta de opinión". REDEN. Revista Española de Estudios Norteamericanos. Alcalá de Henares. vol. XIII. $\mathrm{n}^{\mathrm{o}}$ 23-24, pp. 133-149.

VAn Minnen, Cornelis - Hitton, Sylvia L. (eds.)

2007 Teaching and Studying U.S. History in Europe. Past, Present and Future. Amsterdam. VU University Press.

VÁZQUEZ, Juan Gabriel

2006 "Historia de un malentendido. Lecturas anglosajonas del Quijote". Cuadernos Hispanoamericanos. Madrid. no 670, pp. 53-64.

VILAR GARCÍA, Mar

2000 El español, segunda lengua en los Estados Unidos. De su enseñanza como idioma extranjero en Norteamérica al bilingüismo. Murcia. Universidad de Murcia. $2^{\text {a }}$ ed. 2003.

VILCHES, Gloria F.

2005 "El mito de Carmen en el cine de Hollywood". Archivos de la Filmoteca. Madrid. no 51, pp. 10-15. 